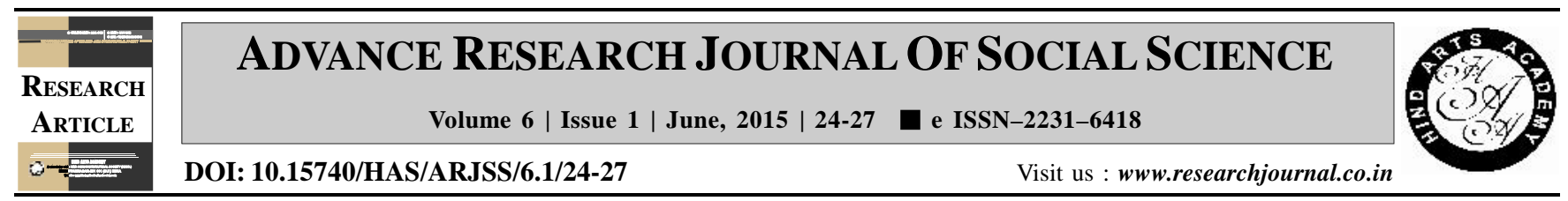

\title{
Role perception and role performance of the members of block farmers advisory committee (BFAC)
}

P.K. Neog, D. Bortamuly*, B.L. Khuhly and D. Borah

Extension Education Institute (NE Region), Assam Agricultural University, JORHAT (ASSAM) INDIA

\section{ARTICLE INFO :}

$\begin{array}{lll}\text { Received } & : & 09.01 .2015 \\ \text { Revised } & : & 08.04 .2015 \\ \text { Accepted } & : & 19.04 .2015\end{array}$

KEY WORDS :

Role perception, Role performance, Block farmers advisory committee, BFAC

HOW TO CITE THIS ARTICLE :

Neog, P.K., Bortamuly, D., Khuhly, B.L. and Borah, D. (2015). Role perception and role performance of the members of block farmers advisory committee (BFAC). Adv. Res. J. Soc. Sci., 6 (1) : 24-27.

*Author for correspondence

\begin{abstract}
The study was undertaken to answer broadly two researchable questions: i) To what extent the members of the Block Farmer's Advisory Committee (BFAC) are perceiving and performing their roles in the 'Support to State Extension Programmes for Extension Reforms (SSEPER) scheme' of the Ministry of Agriculture (MoA), Govt of India (GOI). ii) What measures to be taken by different stakeholders for superior performance by the BFAC members in the schemes? This mega scheme is being implemented in all the states of the country covering 591 districts. Following a purposive cum random sampling technique, 380 numbers of BFAC members were selected as respondents of the study from 2 states viz., Assam and Mizoram. The results revealed that the majority of the BFAC members have medium level of perception and performance of different roles they are to be carried out under the scheme. Positive correlations were found in case of 'training exposure and 'mass media exposure' with the level of role perception and performance of roles by the BFAC members. However, negative association were found in case of 'age', 'education qualification', 'caste', 'operational land holding', 'occupation' and 'annual income' with the level of perception and performance of roles by the BFAC members.
\end{abstract}

